\title{
Clinicopathologic Characteristics and Therapeutic Outcomes of Primary Gastrointestinal Non-Hodgkin's Lymphomas: 10 Years of Experience from a Single Center in Eastern Anatolia
}

\author{
Mehmet Ali Erkurt $^{\mathrm{a}} \quad$ Ismet Aydogdu ${ }^{\mathrm{a}} \quad$ Irfan Kuku $^{\mathrm{a}} \quad$ Emin Kaya $^{\mathrm{a}} \quad$ Yalcin Basaran $^{\mathrm{b}}$ \\ aDepartment of Hematology, Faculty of Medicine, Inonu University, Malatya, and \\ ${ }^{b}$ Department of Internal Medicine, Gulhane Military Medical Academy, Ankara, Turkey
}

\section{Key Words}

Gastrointestinal non-Hodgkin's lymphoma • Prognostic

factors $\cdot$ Clinicopathologic features $\cdot$ Survival

\begin{abstract}
Objective: The objective of this retrospective study was to report the clinicopathological data and the treatment outcomes in patients with primary gastrointestinal non-Hodgkin's lymphoma. Patients and Methods: We carried out a retrospective analysis of 41 patients ( 22 females, 18 males, median age 58 and range 18-90 years) who presented to our department with histopathological diagnosis of primary gastrointestinal non-Hodgkin's lymphoma between 1995 and 2004. Results: The stomach was the most common extranodal site and was seen in 25 of 41 (61\%) patients. At presentation 28 (68.3\%) patients had gastrointestinal symptoms while $27(65.9 \%)$ had B symptoms. The range of follow-up was 2-84 months with a median of 9 months. The overall survival rate was 3 years for 25 (61.2\%) patients. The 3-year overall survival rate was better in patients with earlystage disease (stages I and $\mathrm{II}_{1}$ ) who were treated with surgery plus chemotherapy and/or radiation therapy than in those treated with chemotherapy alone (91.6 vs. $50 \%$, $p<0.05$ ).
\end{abstract}

The disease had a significant impact on both the progression-free survival and overall survival rates. Conclusion: Our data showed that surgical resection prior to postoperative chemotherapy was a better option for patients with earlystage disease with better patient survival.

Copyright ๑ 2009 S. Karger AG, Basel

\section{Introduction}

The gastrointestinal tract is the predominant extranodal site of non-Hodgkin's lymphoma (NHL). Primary gastrointestinal non-Hodgkin's lymphoma (GI-NHL) accounts for $4-20 \%$ of all NHL cases or $30-45 \%$ of all extranodal NHL cases [1]. It has been suggested that the incidence of primary GI-NHL increased over the past two decades [2,3]. In Turkey and Middle Eastern countries, primary extranodal lymphomas constitute more than $25 \%$ of all NHLs. The incidence of primary GI-NHL in Eastern countries seems to be higher than in Western countries [4]. High-grade histopathologic types of gastric lymphoma are more common in Turkey and Middle Eastern countries than in Western countries $[4,5]$.

\section{KARGER}

Fax +4161306 1234

E-Mail karger@karger.ch

www.karger.com
(C) 2009 S. Karger AG, Basel

1011-7571/09/0185-0399\$26.00/0

Accessible online at:

www.karger.com/mpp
Mehmet Ali Erkurt

Konya Education and Research Hospital

Department of Hematology

TR-42090 Konya (Turkey)

Tel. +90 3323236709 ext. 1059, Fax +90332323 6723, E-Mail erkurtali@hotmail.com 
Table 1. Characteristics of 41 patients with GI-NHL

\begin{tabular}{|c|c|c|}
\hline \multirow[t]{2}{*}{ Patient characteristics } & \multicolumn{2}{|c|}{ Patients } \\
\hline & $\mathrm{n}$ & $\%$ \\
\hline Age, years & 41 & \\
\hline$\geq 60$ & 19 & 46.3 \\
\hline$<60$ & 22 & 53.7 \\
\hline \multicolumn{3}{|l|}{ Gender } \\
\hline Female & 22 & 46.3 \\
\hline Male & 19 & 53.7 \\
\hline \multicolumn{3}{|l|}{ Main symptoms } \\
\hline Gastrointestinal symptoms ${ }^{1}$ & 28 & 68.3 \\
\hline Hemorrhage & 4 & 9.8 \\
\hline Perforation & 2 & 4.9 \\
\hline Ileus & 5 & 12.2 \\
\hline Diarrhea & 1 & 2.4 \\
\hline Jaundice & 1 & 2.4 \\
\hline \multicolumn{3}{|l|}{ B symptoms } \\
\hline Present & 27 & 65.9 \\
\hline Not present & 14 & 34.1 \\
\hline \multicolumn{3}{|l|}{ Site of disease } \\
\hline Stomach & 25 & 61 \\
\hline Small bowel & 11 & 26.8 \\
\hline Large bowel & 3 & 7.3 \\
\hline Multiple site & 2 & 4.9 \\
\hline \multicolumn{3}{|l|}{ Endoscopic/surgical findings } \\
\hline Vegetating mass & 12 & 29.3 \\
\hline Ulceration & 6 & 14.6 \\
\hline Ulcero-vegetating mass & 22 & 53.7 \\
\hline Polyposis & 1 & 2.4 \\
\hline Bulky disease $(\geq 10 \mathrm{~cm})$ & 7 & 17.1 \\
\hline \multicolumn{3}{|l|}{ Histopathologic grade } \\
\hline \multicolumn{3}{|l|}{ High-grade B-cell lymphoma } \\
\hline Diffuse large B-cell & 24 & 58.5 \\
\hline \multicolumn{3}{|l|}{ Low-grade B-cell lymphoma } \\
\hline Marginal zone lymphoma (MALT) & 11 & 26.9 \\
\hline Follicular & 1 & 2.4 \\
\hline Mantle cell & 1 & 2.4 \\
\hline T-cell lymphoma & 4 & 9.8 \\
\hline \multicolumn{3}{|l|}{ WHO performance status } \\
\hline 0 & 25 & 61.1 \\
\hline 1 & 12 & 29.2 \\
\hline 2 & 3 & 7.3 \\
\hline 3 & 1 & 2.4 \\
\hline 4 & 0 & 0 \\
\hline \multicolumn{3}{|l|}{ Histopathology } \\
\hline T cell & 4 & 9.8 \\
\hline B cell & 37 & 90.2 \\
\hline \multicolumn{3}{|l|}{ Lugano staging } \\
\hline Stage I & 6 & 14.6 \\
\hline Stage II1 & 8 & 19.5 \\
\hline Stage II2 & 5 & 12.2 \\
\hline Stage IIE & 9 & 22 \\
\hline Stage IV & 13 & 31.7 \\
\hline
\end{tabular}

MALT $=$ Mucosa-associated lymphoid tissue.

${ }^{1}$ Nausea, vomiting and/or abdominal pain.
More than half of primary GI-NHLs arise in the stomach and this is frequently followed by the small intestine [1]. The predominant symptoms are epigastric pain, dyspepsia, nausea and vomiting. Upper or lower gastrointestinal bleeding (hematemesis or melena) occurs at the outset in $20-30 \%$ of cases, while ileus and perforation are quite rare $[6,7]$.

The management of nodal NHL is well established, but much debate and controversy still remains regarding the optimal regimen in GI-NHL, particularly in gastric lymphomas. Surgery, radiation therapy and chemotherapy have been used alone or in combination [8]. The efficacy of surgery in adequately controlling tumors, especially gastric lymphomas, has been demonstrated in some studies $[9,10]$. It was pointed out that surgery alone or surgery combined with chemotherapy and/or radiotherapy may increase survival rates, and that a conservative treatment approach using radiotherapy and/or chemotherapy as the initial treatment modality without primary resection may preserve the stomach. In several studies, multiple alternative chemotherapy regimens have also been introduced in the management of advanced stages of lymphoma (stages $\mathrm{II}_{2}$, IIE, and IV), and modern techniques of radiotherapy have been proven to be quite effective in its treatment $[11,12]$. No benefit from surgery was reported from these controlled clinical trials in current publications $[13,14]$.

Most of the studies published so far were retrospective. Only a few of them were prospective controlled randomized trials and the sample sizes of these reports were too small to achieve adequate statistical power $[7,15]$. The objective of this study was to assess the clinicopathologic characteristics and therapeutic outcomes of primary GINHL.

\section{Patients and Methods}

\section{Patients}

This retrospective study was based on a review of medical records from patients with primary GI-NHL diagnosed at Turgut Ozal Medical Center, Department of Hematology, between January 1995 and December 2004. This review included clinical features, histopathological classification, site of involvement, efficacy of different treatment modalities and prognostic factors for improved survival. All subjects fulfilled the diagnostic criteria for primary GI-NHL as defined by Lewin et al. [16]. Fifty medical charts were reviewed, and 41 patients were included in the study. Nine patients were ineligible because of insufficient data (table 1). Treatment modalities were compared with age, gender, histopathological grade, B- or T-cell lineage, stage, and location of disease. 


\section{Histologic Classification}

All histologic materials were obtained by endoscopic biopsy and surgery. These tissue specimens were stained routinely with hematoxylin and eosin (H\&E). Immunohistochemical staining for CD3 and CD20 was performed on all 41 specimens. In some selected cases, additional staining was done using antibodies CD5, CD10, CD23, CD30, CD56, cyclin D1, bcl-2, bcl-6, c-myc, p53, Ki-67, immunoglobulin light chains $(\kappa, \lambda)$, or $\beta 1$. All H\&E and immunohistochemical slides were reviewed separately by 2 observers and a common consensus was reached in all cases. All patients were reviewed and classified histopathologically using the WHO classification [17] of low-grade B-cell lymphomas [marginal zone B-cell lymphoma of MALT type (MALT lymphoma), follicular lymphoma, and mantle cell lymphoma], high-grade Bcell lymphomas (diffuse large B-cell lymphoma), and T-cell lymphoma.

\section{Staging and Diagnostic Procedures}

All patients were staged according to the Lugano International Conference classification ( $\mathrm{I}_{1} \mathrm{II}_{1}, \mathrm{II}_{2}$, IIE, and IV), which was submitted as a modified version of the Ann Arbor criteria for GINHL [18]. All patients underwent staging procedures that included chest radiograms, abdominal ultrasonography, computed tomography of the chest and abdomen, radiographic studies of the duodenum and small intestine, upper gastrointestinal endoscopy, and bone marrow biopsy. The macroscopic type of lymphoma was either vegetating mass, ulceration, ulcero-vegetating mass, polyposis or bulky disease $(\geq 10 \mathrm{~cm})$. This typing was determined based on the resected specimens or endoscopic findings. Response criteria and end points were reported according to published guidelines [19]. Patients were examined at 3-monthly intervals for the first year and 6-monthly thereafter.

\section{Treatment}

An initial surgical treatment decision, in which the hematologist and/or the radiation oncologist were not involved, was made according to the surgeon's preference. Initial surgery was performed in 19 patients: 8 patients underwent total or subtotal gastrectomy, 4 had Roux-en-Y anastomosis (a choledochojejunostomy performed for biliary bypass), 5 had tumor resection, and 2 had debulking surgery. Of these patients, 12 received chemotherapy, 6 were treated with chemotherapy plus radiotherapy $(3,600$ cGy total abdominal $\pm 600 \mathrm{cGy}$ boost radiotherapy to tumor bed), and 1 with chemotherapy plus palliative surgery. Twelve patients received chemotherapy alone while 5 received chemotherapy plus radiotherapy, and 5 patients with poor performance status received only supportive care.

If there was any evidence of residual disease on physical examination or on imaging studies, and/or the presence of close or microscopically positive surgical margins or lymph nodes greater than $1 \mathrm{~cm}$ in size, additional cycles of chemotherapy were administered. Even if additional chemotherapy was not wholly successful in controlling the disease, radiotherapy was used. Finally, if there was no response to adjuvant treatment after surgery, second-line chemotherapy was administered.

Cyclophosphamide, doxorubicin, vincristine, and prednisolone $(\mathrm{CHOP})$ and other antracycline-containing regimens were the most frequently used regimens in 36 of the 41 patients (table 2). In general, patients were treated with 6-8 cycles of the classical lymphoma regimen (CHOP-like regimens). For treating pa-
Table 2. Treatment modalities of all patients

\begin{tabular}{lrr}
\hline Treatment modalities & \multicolumn{2}{l}{ Patients } \\
\cline { 2 - 3 } & $\mathrm{n}$ & $\%$ \\
\hline Surgery + chemotherapy & 12 & 29.3 \\
Surgery + chemotherapy + radiotherapy & 6 & 14.6 \\
Chemotherapy + palliative surgery & 1 & 2.4 \\
Chemotherapy + radiotherapy & 5 & 12.2 \\
Chemotherapy alone & 12 & 29.3 \\
Supportive care only & 5 & 12.2 \\
Total & 41 & 100 \\
\hline
\end{tabular}

tients with early-stage disease, if the involved field radiotherapy was deemed necessary as a part of pretreatment in advance, a total of 4 cycles of chemotherapy were administered.

\section{Statistical Analysis}

Statistical analysis was performed using SPSS (Statistical Program for Social Sciences, version 15.0, Chicago, Ill., USA). Overall survival (OS) and progression-free survival (PFS) rates were calculated with the life table Kaplan-Meier method, starting from the date of diagnosis to the date of death or last follow-up visit. The statistical significance of observed differences was assessed using the log-rank test. The prognostic value of different variables for the outcome was assessed by univariate and multivariate analysis using the Cox regression model. The level of statistical significance was defined as $\mathrm{p}<0.05$.

\section{Results}

Primary GI-NHL accounted for 9.7\% of all lymphomas. Of the 41 patients with histopathological diagnosis of primary GI-NHL, 19 were males and 22 females with a median age of 58 years (range 18-90). Patients with intestinal involvement were younger as compared with patients with gastric involvement (median age 49 vs. 60 years). Stomach, small intestine, large intestine, and synchronized multiple gastrointestinal site involvement (ileocecal region was considered as small intestinal involvement) occurred in 25 (61\%), 11 (26.8\%), 3 (7.3\%), and 2 (4.9\%) patients, respectively. According to the Lugano staging system, 6 patients (14.6\%) were stage I, 8 (19.5\%) stage $\mathrm{II}_{1}, 5(12.2 \%)$ stage $\mathrm{II}_{2}, 9$ (22\%) stage IIE, and 13 (31.7\%) stage IV disease. According to the WHO performance status, 25 patients $(61.1 \%)$ were 0,12 patients (29.2\%) 1, 3 patients (7.3\%) 2, and 1 patient (2.4\%) 3 (table 1). 


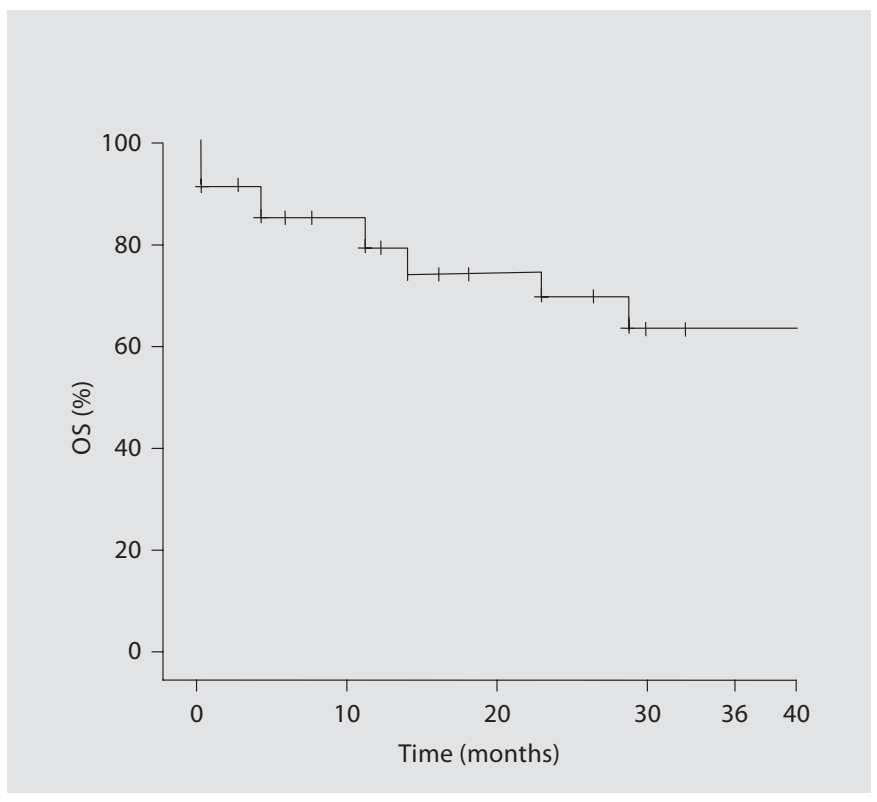

Fig. 1. OS of all primary GI-NHL patients.

Initial presenting symptoms were: upper gastrointestinal symptoms (nausea, vomiting and/or abdominal pain: $\mathrm{n}=28$; jaundice: $\mathrm{n}=1$; diarrhea: $\mathrm{n}=1$ ), and emergency admission: $\mathrm{n}=11$ (patients with perforation: $\mathrm{n}=2$; with gastrointestinal bleeding: $n=4$; with ileus: $n=5$ ). In 41 patients, who were diagnosed endoscopically or surgically, a tumoral mass was detected. But 6 patients presented with solely gastric ulcerations. This finding shows that biopsy is often required in gastric ulcerations in order to confirm the diagnosis of lymphoma. At the time of diagnosis, 27 (65.9\%) patients had B symptoms (table 1).

\section{Endoscopic and/or Surgical Findings}

Endoscopic and surgical findings obtained from the 41 registries were gastric ulcerations: $\mathrm{n}=6(14.6 \%)$, vegetating masses: $\mathrm{n}=12(29.3 \%)$, ulcero-vegetating masses: $\mathrm{n}=22(53.7 \%)$, multiple polyposis: $\mathrm{n}=1(2.4 \%)$, and bulky disease $(>10 \mathrm{~cm}): \mathrm{n}=7(17 \%$, table 1$)$.

\section{Histopathology}

Based on the WHO classification, high-grade and advanced-stage disease was relatively common: 24 patients (58.5\%) had diffuse large B-cell lymphoma. Lowgrade B-cell lymphoma was less common: MALT: $\mathrm{n}=11$ (26.9\%); follicular lymphoma: $\mathrm{n}=1(2.4 \%)$; mantle cell: $\mathrm{n}=1(2.4 \%)$, and T-cell disease: $\mathrm{n}=4(9.8 \%)$. Based on our working formulation, 5 (12.2\%) patients had low-grade,

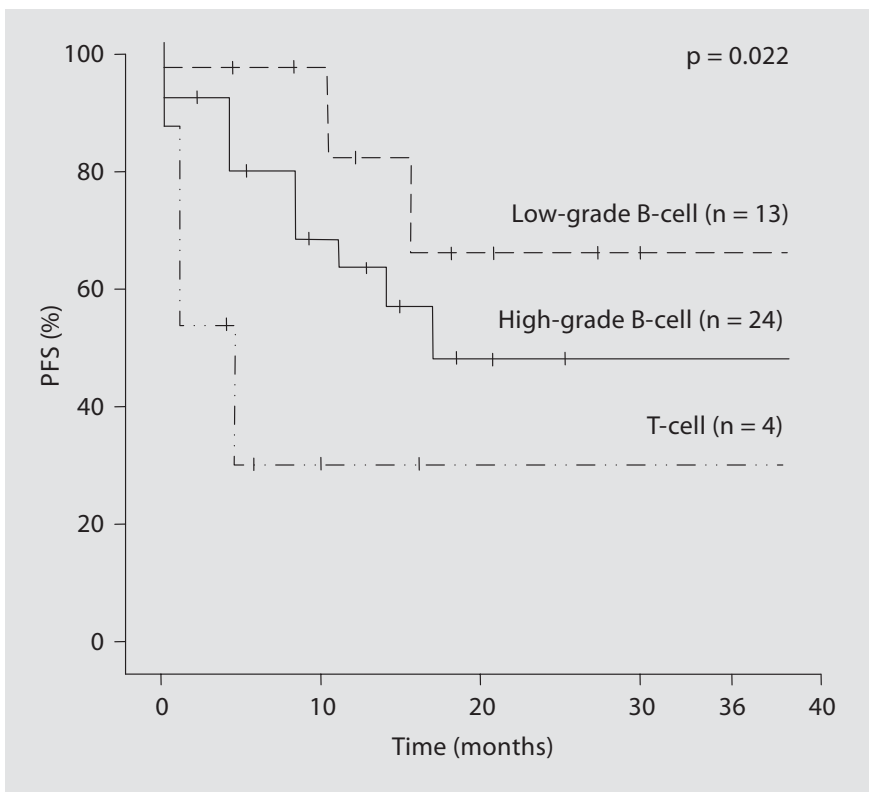

Fig. 2. Effect of histopathological grades on PFS in low-grade, high-grade and T-cell primary GI-NHL.

33 (80.5\%) intermediate-grade, and 3 (7.3\%) high-grade disease. Immunohistochemically $4(9.8 \%)$ patients had neoplastic cells that were positive for the T-cell markers (table 1).

\section{Survival Analysis}

In the median follow-up of 9 months (range 2-84 months), 6 of 41 patients died. Febrile neutropenia was the cause of death in 1 (which was chemotherapy-induced in an advanced stage), hemorrhagia in another (secondary to thrombocytopenia which was chemotherapy-related in an early stage), and the remaining 4 died due to disease progression (all of whom had advanced-stage disease). Five patients with only supportive care were not included in prognostic factor analysis. The 3 -year OS rate was $61.2 \%$ in all patients (fig. 1). The 3-year OS rates were 78,65 , and $42 \%$ among patients with low, intermediate, and high grade, respectively (fig. 2): 82,63 , and $29 \%$ among those with stage $\mathrm{I}_{-} \mathrm{II}_{1}$, stage $\mathrm{II}_{2}-\mathrm{IIE}$, and stage IV disease, respectively (fig. 3). The 3-year PFS rates were 68, 49 , and $30 \%$ among patients with low-grade, high-grade and T-cell lymphoma ( $\mathrm{p}=0.022)$, respectively (fig. 2$)$, and 71,52 , and $26 \%$ among those with stage $\mathrm{I}_{-} \mathrm{II}_{1}$, stage $\mathrm{II}_{2}-$ IIE, and stage IV disease, respectively ( $\mathrm{p}=0.018$, fig. 3 ).

Univariate analysis of the influence of age, gender, B symptoms, stage and histopathologic grade of disease, and T-cell marker positivity on patient survival showed 


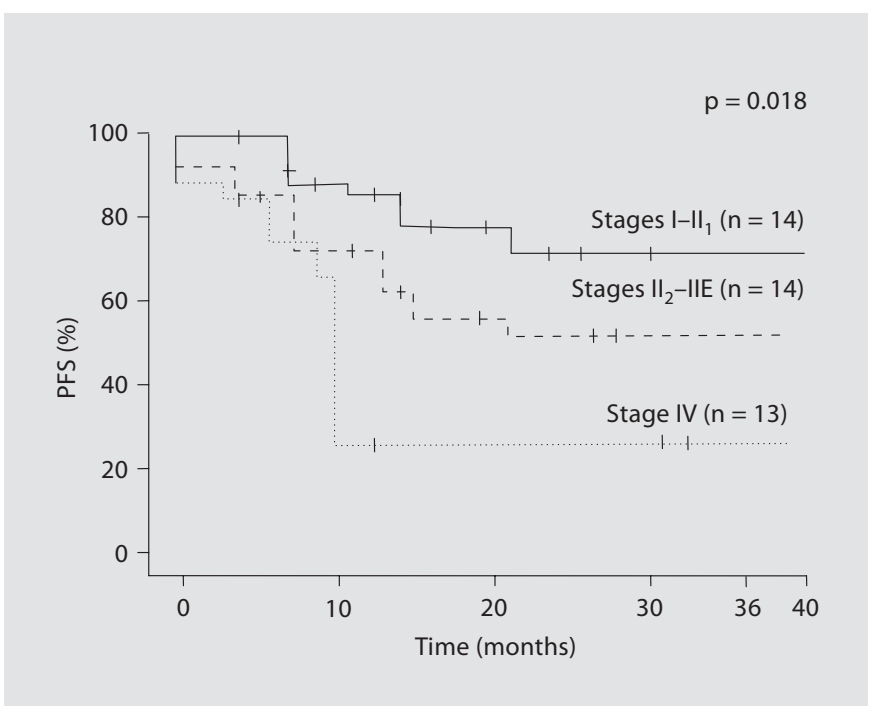

Fig. 3. PFS of early- and advanced-stage primary GI-NHL.

Table 3. Cox multivariate analysis for OS

\begin{tabular}{llll}
\hline Parameters & Odds ratio & $95 \%$ CI & p value \\
\hline Sex & 1.0357 & $0.39-2.95$ & NS \\
Localization & 1.3987 & $0.57-3.12$ & NS \\
Stage & 2.1285 & $1.12-4.83$ & 0.02 \\
Grade & 1.8824 & $0.71-4.21$ & NS \\
Age $(<60$ or $\geq 60$ years $)$ & 0.7841 & $0.27-1.96$ & NS \\
Surgery & 1.0274 & $0.36-1.94$ & NS \\
B symptom positivity & 1.7432 & $0.59-5.12$ & NS \\
\hline
\end{tabular}

that advanced stage, high-grade histopathology, and the presence of B symptoms, which negatively affected the PFS rate ( $p<0.05$, fig. $2-4)$, were the statistically significant factors. However, Cox regression multivariate analysis revealed that only advanced stage correlated with OS rate $(\mathrm{p}=0.02$, table 3$)$. According to Cox regression multivariate analysis, advanced stage significantly and negatively affected PFS ( $p=0.04)$, also the presence of B symptoms affected PFS to a significant extent ( $\mathrm{p}=0.04$, table 4).

The 3-year OS rate was better in stage $\mathrm{I}$ and $\mathrm{II}_{1}$ patients who were treated with surgery plus chemotherapy $( \pm$ radiotherapy) than in those treated with chemotherapy alone ( $\mathrm{p}=0.036$, fig. 5 ). In the early stage, surgery plus chemotherapy achieved significantly better results than chemotherapy alone in terms of higher overall response

Therapeutic Outcomes of Gastrointestinal Non-Hodgkin's Lymphomas

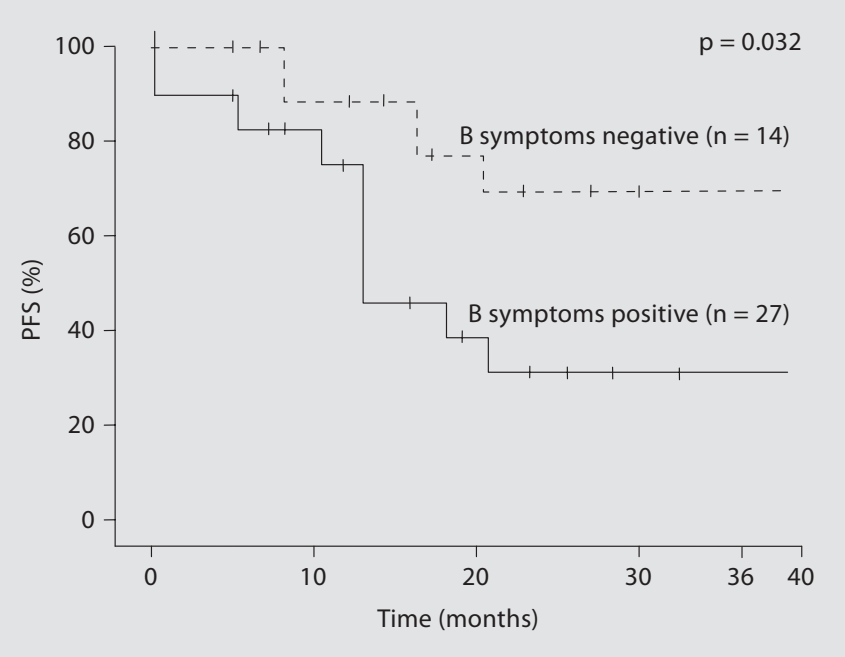

Fig. 4. Effect of the presence of B symptoms on PFS.

Table 4. Cox multivariate analysis for PSF

\begin{tabular}{llll}
\hline Parameters & Odds ratio & $95 \%$ CI & p value \\
\hline Sex & 1.1245 & $0.41-2.62$ & NS \\
Localization & 0.7621 & $0.28-2.12$ & NS \\
Stage & 1.7538 & $1.06-3.75$ & 0.04 \\
Grade & 1.3676 & $0.54-3.42$ & NS \\
Age (<60 or $\geq 60$ years) & 0.9430 & $0.36-2.01$ & NS \\
Surgery & 1.1743 & $0.47-2.28$ & NS \\
B symptom positivity & 2.2953 & $0.91-5.83$ & 0.04 \\
\hline
\end{tabular}

rate (complete response + partial response, 100 vs. $58.3 \%$ ), 3 -year PFS (83.3 vs. $41.6 \%$ ) and 3-year OS rates (91.6 vs. $50 \%)$. In the advanced stage, there was no difference in the 3 -year PFS ( 25 vs. $33.3 \%$ ), 3-year OS ( 41.6 vs. $50 \%$ ) and overall response (33.3 vs. $41.6 \%)$ rates between the two groups. In advanced-stage disease, surgical resection seemed to be a disadvantage, but it was not found to be statistically significant $(\mathrm{p}=0.6)$.

\section{Effect of Surgery on Survival}

The analysis of the effect of surgery in patients with completely resectable early-stage (stages $\mathrm{I}$ and $\mathrm{II}_{1}$ ) and unresectable advanced-stage (stages $\mathrm{II}_{2}$, IIE, and IV) disease showed no difference in OS and PFS of patients based on histopathological and clinical variables (grade, age, and B symptoms). 


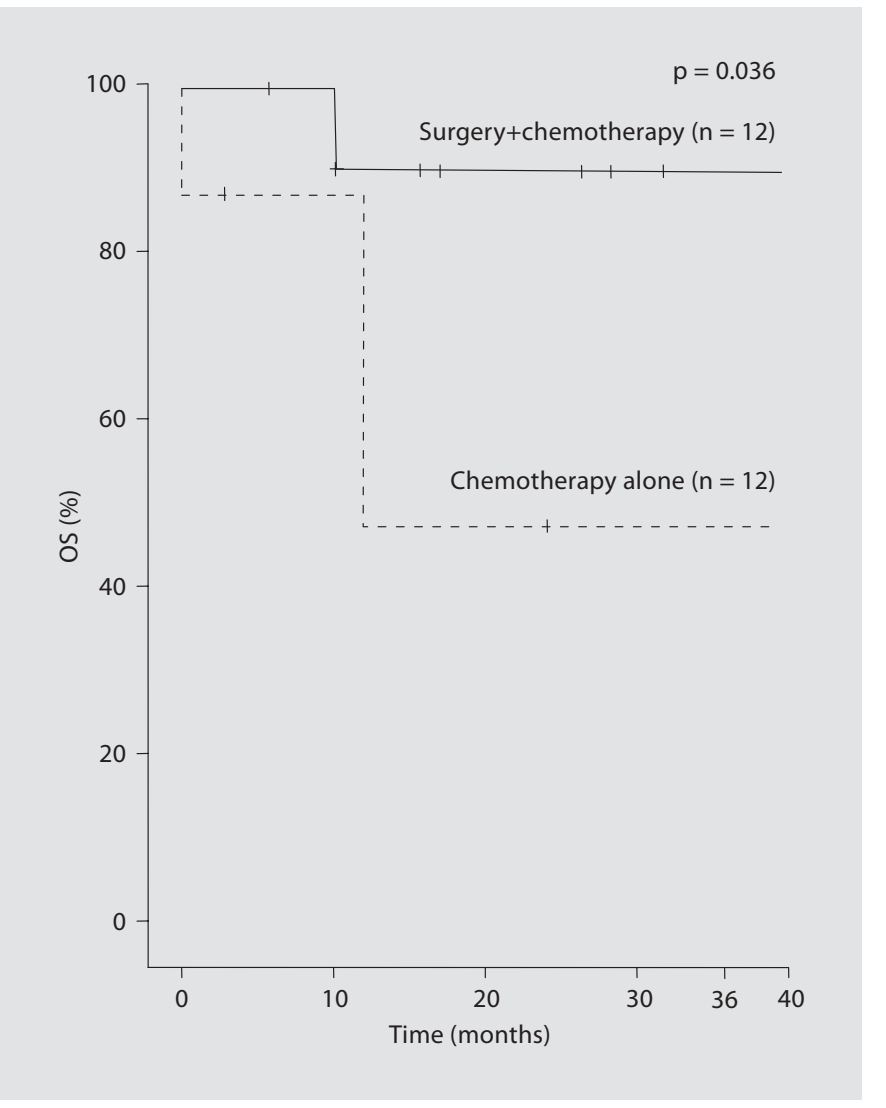

Fig. 5. Effect of surgery on OS in early-stage primary GI-NHL.

\section{Discussion}

Primary GI-NHL typically presents with nonspecific signs and symptoms attributable to the site of involvement, extent and histologic subtype of the disease, and the performance status of the patient. Gastrointestinal localizations are the most common sites of primary extranodal lymphoma as in our study (table 5). The previously reported predominant symptoms of epigastric pain, dyspepsia, nausea and vomiting, anorexia and very frequent weight loss were also observed in our study where $68.3 \%$ of patients presented with gastrointestinal symptoms such as abdominal pain, nausea and vomiting. Eastern countries have a higher incidence of primary GI-NHL than Western countries $[4,5,20]$. Geographic variations in the prevalence of environmental factors may be the cause of this difference. However, the incidence of primary GI-NHL in the US [3], Europe [21] and Turkey [4] has increased over the past two decades. Advances in diagnostic procedures may have led to an improvement in the accuracy in the diagnosis of lymphoma. Increasing exposure or susceptibility to risk factors, such as ultraviolet light, chemicals, and excessive protein or fat in the diet, also may have contributed to this increase [20]. With regard to gender distribution, in contrast to previous reports $[1,5,7,8]$, there was a slight female predominance in our series (with a female:male ratio of 1.15:1). This difference may support the hypothesis that gender-specific, constitutional or behavioral factors can play a role in the development of GI-NHL.

Advanced stages of gastric lymphoma are more prevalent in Turkey, Middle Eastern and Far Eastern countries than in Western countries. Compared with Western reports of $10-31 \%, 53.7 \%$ of our patients had disseminated disease at the time of diagnosis (stages $\mathrm{II}_{2} \mathrm{E}-\mathrm{IV}$ ), which is similar to eastern data (52\%) [2-5]. Poor prognostic factors were more frequent in our patients than in Western countries.

Optimal management of primary GI-NHLs remains controversial. Surgery, radiotherapy and chemotherapy have been used either alone or in combination. Currently, the most controversial issue in the treatment of primary GI-NHLs is to determine whether or not the surgical treatment approach is necessary as the primary treatment modality. In patients with completely resectable early-stage disease, surgery has more of an advantage but could delay the use of chemotherapy, could be associated with some morbidity, and may also have a mortality rate of up to $10 \%$ [22]. Furthermore, it has also been suggested that surgery does not have a significant influence on OS and PFS rates. Currently, several series have reported that surgery is not indicated unless complications such as perforation, hemorrhage or obstruction occur, which cannot be managed conservatively [8]. Avilés et al. $[13,14]$ reported on the role of surgery in high-grade MALT, lowgrade MALT and diffuse large B-cell gastric lymphomas. No benefit from surgery was found from these controlled clinical trials. Primary chemotherapy or radiotherapy is currently recommended in cases of localized or advanced disease $[1,7,23]$. In our series, 2 deaths were due to surgical complications (one due to intra-abdominal infection and the other due to hemorrhage). Although it was stated that surgery has the advantage of total tumor removal and limits the risk of hemorrhage and perforation, this was not supported by the analysis of our patients.

In a randomized study on gastric NHL, results after chemotherapy or surgery plus chemotherapy (91\% survival rate at 10 years) were significantly superior to results after surgery alone (54\% survival rate at 10 years) or surgery plus radiotherapy (53\% survival rate at 10 years) [22]. 
Table 5. Sites of origin in primary GI-NHL in the literature

\begin{tabular}{|c|c|c|c|c|c|c|}
\hline \multirow[t]{2}{*}{ Author } & \multirow[t]{2}{*}{ Nation } & \multirow[t]{2}{*}{ Patients } & \multicolumn{4}{|c|}{ Anatomic sites of origin, $\mathrm{n}(\%)$} \\
\hline & & & gastric & intestinal & combined & others \\
\hline Radaszkiewicz et al. [25] & Austria & 372 & $258(69)$ & $71(19)$ & $8(2.2)^{\mathrm{a}}$ & $35(9.4)^{b}$ \\
\hline d'Amore et al. [1] & Denmark & 306 & $175(57)$ & $109(36)$ & $22(7.2)$ & - \\
\hline Liang et al. [26] & Hong Kong & 425 & $238(56)$ & $184(43)$ & $\mathrm{ND}$ & $3(0.8)^{\mathrm{c}}$ \\
\hline Gurney et al. [21] ${ }^{\mathrm{d}}$ & United Kingdom & 1,047 & $463(44)$ & $440(42)$ & ND & $144(14)^{\mathrm{b}}$ \\
\hline Koch et al. [7] & Germany & 371 & $277(75)$ & $70(19)$ & $24(6.5)$ & - \\
\hline Nakamura et al. [20] & Japan & 455 & $342(75)$ & $96(21)$ & $17(3.7)$ & - \\
\hline Current study (2008) & Turkey & 41 & $25(61)$ & $14(34.1)$ & $2(4.9)$ & - \\
\hline
\end{tabular}

ND $=$ Not described. ${ }^{a}$ Cases involving multiple gastrointestinal tract organs. ${ }^{b}$ Unspecified. ${ }^{c}$ Cases with primary esophageal lymphoma. ${ }^{\mathrm{d}}$ Registry data without prognostic analysis.

However, other investigators showed no difference in survival rates after chemotherapy alone versus surgery plus chemotherapy $[8,23]$. In our series, surgery in combination with chemotherapy (3-year OS rates, 91.6\%) was significantly superior to chemotherapy alone (3-year OS rates, 50\%) in the treatment of early-stage disease ( $\mathrm{p}=$ $0.03)$. In the early stage, among the patients treated with surgery plus chemotherapy (83.3\%), 3-year PFS rate was statistically significantly higher than among those who received chemotherapy $(41.6 \%)$ alone $(\mathrm{p}=0.06)$. In the early stage, among the patients treated with surgery plus chemotherapy (100\%), the OS rate was statistically significantly higher than the rates among those who received chemotherapy (58.3\%) alone $(\mathrm{p}=0.01)$. However, surgery had no advantage in terms of 3-year OS rates for patients with advanced-stage disease ( 41.6 vs. $50 \%, \mathrm{p}=$ 0.11 ). In the advanced stage, there was no significant difference in 3-year PFS rates between the two groups ( $25 \mathrm{vs}$. $33.3 \%)$. There was no significant difference in the overall response rates between the two groups (33.3 vs. $41.6 \%$ ). However, we should mention that the number of patients was too low to come to a conclusion.

Primary gastric lymphomas are most commonly of B-cell lineage, while primary gastric T-cell lymphomas are extremely rare and have a poor prognosis [24]. Our findings are consistent with the results of previous research. The median follow-up time, however, was too short (only 9 months). This is a major disadvantage, when survival or prognostic factor analysis are performed. It is noteworthy that among the 41 patients of the study, only 6 died, 2 from complications and 4 from disease progression. Among those 4 patients $(9.8 \%)$ who succumbed to disease, 3 had T-cell NHL. Therefore, any survival esti- mates and comparisons were based on events caused by complications or T-cell NHL and only one event was attributed to disease progression in a patient with B-cell NHL. If the follow-up period had been longer, probably more events would have occurred due to B-NHL progression.

The results of our study showed that the stage of the disease was the most important prognostic factor affecting clinical outcome. Patients with early-stage disease had significantly longer 3-year PFS and 3-year OS rates than patients with advanced stage-disease $(\mathrm{p}<0.05$, tables 3,4$)$. Our results were similar to those observed in the studies by Koch et al. [7] and Eser at al. [5].

\section{Conclusion}

Surgical resection followed by postoperative chemotherapy may be a viable option for patients with earlystage disease which may lead to improved patient survival but since the number of patients in our study was small, our result should be interpreted with caution. Further randomized prospective studies with larger sample size should be carried out to clarify the optimal management of primary gastrointestinal lymphoma. 


\section{References}

1 D'Amore F, Brincker H, Gronbaek K, Thorling K, Pedersen M, Jensen MK, Andersen E, Pedersen NT, Mortensen LS: Non-Hodgkin's lymphoma of the gastrointestinal tract: a population based analysis of incidence, geographic distribution, clinicopathologic presentation features, and prognosis. Danish Lymphoma Study Group. J Clin Oncol 1994; 12:1673-1684.

$\checkmark 2$ Hayes J, Dunn E: Has the incidence of primary gastric lymphoma increased? Cancer 1989;63:2073-2076.

3 Devesa SS, Fears T: Non-Hodgkin's lymphoma time trends: United States and international data. Cancer Res 1992;52:5432-5440.

-4 Isikdogan A, Ayyildiz O, Buyukcelik A, Arslan A, Tiftik N, Buyukbayram H, Muftuoglu E: Non-Hodgkin's lymphoma in southeast Turkey: clinicopathologic features of 490 cases. Ann Hematol 2004;83:265269.

5 Eser B, Kaplan B, Unal A, Canoz O, Altuntas F, Sari HI, Er O, Ozkan M, Kucuk C, Arar M, Gursoy S, Cetin M: Clinicopathologic characteristics and therapeutic outcomes of primary gastrointestinal non-Hodgkin's lymphomas in Central Anatolia, in Turkey. Yonsei Med J 2006;47:22-33.

6 Cogliatti SB, Schmid U, Schumacher U, Eckert F, Hansmann ML, Hedderich J, Takahashi H, Lennert K: Primary B cell gastric lymphoma: a clinicopathological study of 145 patients. Gastroenterology 1991;101: 1159-1170.

7 Koch P, del Valle F, Berdel WE, Willich NA, Reers B, Hiddemann W, Grothaus-Pinke B, Reinartz G, Brockmann J, Temmesfeld A, Schmitz R, Rübe C, Probst A, Jaenke G, Bodenstein H, Junker A, Pott C, Schultze J, Heinecke A, Parwaresch R, Tiemann M: Primary gastrointestinal non-Hodgkin's lymphoma: anatomic and histologic distribution, clinical features, and survival data of 371 patients registered in the German multicenter study GIT NHL 01/92. J Clin Oncol 2001;19:3861-3873.

8 Papaxoinis G, Papageorgiou S, Rontogianni D, Kaloutsi V, Fountzilas G, Pavlidis N, Dimopoulos M, Tsatalas C, Xiros N, Economopoulos T: Primary gastrointestinal nonHodgkin's lymphoma: a clinicopathologic study of 128 cases in Greece. A Hellenic Cooperative Oncology Group study (HeCOG). Leuk Lymphoma 2006;47:2140-2146.
9 Dragosics B, Bauer P, Radaskiewicz T: Primary gastrointestinal non-Hodgkin's lymphomas: a retrospective clinicopathologic study of 150 cases. Cancer 1985;55:10601073.

10 Maor MH, Velasquez WS, Fuller LM, Silvermintz KB: Stomach conservation in stages IE and IIE gastric non-Hodgkin's lymphoma. J Clin Oncol 1990;8:266-271.

11 Gobbi PG, Dionigi P, Barbieri F, Corbella F, Bertoloni D, Grignani G, Jemos V, Pieresca $\mathrm{C}$, Ascari E: The role of surgery in the multimodal treatment of primary gastric nonHodgkin's lymphomas: a report of 76 cases and review of the literature. Cancer 1990;65: 2528-2536.

12 Sonnen R, Calavrezos A, Grimm HA, Kuse $\mathrm{R}$ : Combined conservative treatment of localized stomach lymphoma. Dtsch Med Wochenschr 1994;119:863-868.

$\checkmark 13$ Avilés A, Neri N, Nambo MJ, Huerta-Guzman J, Cleto S: Surgery and chemotherapy versus chemotherapy as treatment of highgrade MALT gastric lymphoma. Med Oncol 2006;23:295-300.

14 Avilés A, Nambo MJ, Neri N, Talavera A, Cleto S: Mucosa-associated lymphoid tissue (MALT) lymphoma of the stomach: results of a controlled clinical trial. Med Oncol 2005;22:57-62.

15 Ruskone-Fourmestraux A, Aegerter P, Delmer A, Brousse N, Galian A, Rambaud JC: Primary digestive tract lymphoma: a prospective multicentric study of 91 patients. Groupe d'Etude des Lymphomes Digestifs. Gastroenterology 1993;105:1662-1671.

16 Lewin KJ, Ranchod M, Dorfman RF: Lymphomas of the gastrointestinal tract: a study of 117 cases presenting with gastrointestinal disease. Cancer 1978;42:693-707.

17 Jaffe ES, Harris NL, Stein H, Vardiman JW: World Health Organization Classification of Tumours. Pathology and Genetics of Tumours of Haematopoietic and Lymphoid Tissues. Lyon, IARC Press, 2001.

18 Rohatiner A, d'Amore F, Coiffier B, Crowther D, Gospodarowicz M, Isaacson P, Lister TA, Norton A, Salem P, Shipp M: Report on a workshop convened to discuss the pathological and staging classifications of gastrointestinal tract lymphoma. Ann Oncol 1994;5: 397-400.
19 Cheson BD, Horning SJ, Coiffier B, Shipp MA, Fisher RI, Connors JM, Lister TA, Vose J, Grillo-López A, Hagenbeek A, Cabanillas F, Klippensten D, Hiddemann W, Castellino R, Harris NL, Armitage JO, Carter W, Hoppe $\mathrm{R}$, Canellos GP: Report of an international workshop to standardize response criteria for non-Hodgkins lymphomas. J Clin Oncol 1999;17:1244-1253.

20 Nakamura S, Matsumoto T, Lida M, Yao $\mathrm{T}$, Tsuneyoshi M: Primary gastrointestinal lymphoma in Japan: a clinicopathologic analysis of 455 patients with special reference to its time trends. Cancer 2003;97: 2462-2473.

-21 Gurney KA, Cartwright RA, Gilman EA: Descriptive epidemiology of gastrointestinal non-Hodgkin's lymphoma in a populationbased registry. Br J Cancer 1999;79:19291934.

22 Mafune K, Tanaka Y, Suda Y, Izumo T: Outcome of patients with non-Hodgkin's lymphoma of the stomach after gastrectomy: clinicopathologic study and reclassification according to the revised European-American lymphoma classification. Gastric Cancer 2001;4:137-143.

23 Koch P, Probst A, Berdel WE, Willich NA, Reinartz G, Brockmann J, Liersch R, del Valle F, Clasen H, Hirt C, Breitsprecher R, Schmits R, Freund M, Fietkau R, Ketterer P, Freitag EM, Hinkelbein M, Heinecke A, Parwaresch R, Tiemann M: Treatment results in localized primary gastric lymphoma: data of patients registered within the German Multicenter Study (GIT NHL 02/96). J Clin Oncol 2005;23:7050-7059.

24 Park YH, Kim WS, Bang SM, Lee SI, Kang HJ, Na II, Yang SH, Lee SS, Uhm JE, Kwon JM, Kim K, Jung CW, Park K, Ko YH, Ryoo BY: Primary gastric lymphoma of T-cell origin: clinicopathologic features and treatment outcome. Leuk Res 2006;30:12531258.

25 Radaszkiewicz T, Dragosics B, Bauer P: Gastrointestinal malignant lymphomas of the mucosa-associated lymphoid tissue: factors relevant to prognosis. Gastroenterology 1992;102:1628-1638.

26 Liang R, Todd D, Chan TK, Chiu E, Lie A, Kwong YL, Choy D, Ho FC: Prognostic factors for primary gastrointestinal lymphoma. Hematol Oncol 1995;13:153-163. 